\title{
ANATOMIA DA MADEIRA DE PLINIA RIVULARIS (CAMB.) ROTMAN ${ }^{1}$
}

\author{
LUCIANO DENARDI ${ }^{2}$ JOSÉ NEWTON CARDOSO MARCHIORI ${ }^{3}$ \\ MARCOS ROBERTO FERREIRA ${ }^{4}$
}

\section{RESUMO}

A estrutura anatômica da madeira de Plinia rivularis (Camb.) Rotman é descrita e ilustrada com fotomicrografias.

Palavras-chave: Anatomia da madeira, Myrtaceae, Plinia rivularis.

\section{ABSTRACT}

The wood of Plinia rivularis (Camb.) Rotman is anatomically described and illustrated with photomicrographs.

Key words: Wood anatomy, Myrtaceae, Plinia rivularis.

\section{INTRODUÇÃO}

A Família Myrtaceae compreende cerca de 100 gêneros e 3.000 espécies de árvores e arbustos que se distribuem por todos os continentes, com exceção da Antártida, mas com nítida predominância nas regiões tropicais e subtropicais do mundo. No Rio Grande do Sul, as Mirtáceas ocupam posição de destaque, chegando, por vezes, a impor-se na fisionomia da vegetação (Marchiori \& Sobral, 1997).

O gênero Plinia L. reúne cerca de 20 espécies de árvores e arvoretas (Rotman, 1982), quatro das quais são nativas no Rio Grande do Sul. Conhecida regionalmente pelos nomes de guapuriti, baporeti ou guamirim, Plinia rivularis (Camb.) Rotman é árvore de porte pequeno (até $15 \mathrm{~m}$ ) e ampla dispersão geográfica, ocorrendo do Pará ao norte do Uruguai. Bastante freqüente nas florestas da Depressão Central, Alto Uruguai e bacia do Ibicuí (Marchiori \& Sobral, 1997), a espécie habita sobretudo planícies aluviais e início de encostas. Sobre esse ponto, Legrand \& Klein (1978) assinalam que sua presença é mais esporádica ou irregular na mata pluvial da encosta atlântica e na zona da matinha nebular, próximo aos Aparados da Serra Geral.

Sobre a anatomia da madeira, Metcalfe \& Chalk (1972) referem, para a família, a presença de vasos usualmente pequenos, numerosos e solitários, de elementos de comprimento médio até grande, com placas de perfuração simples, de pontoações intervasculares alternas, pequenas e ornamentadas, e de raios usualmente heterogêneos, exclusivamente unisseriados ou multisseriados, com 2-3 (até 6) células de largura. O parênquima, tipicamente apotraquealdifuso ou em faixas unisseriadas, em madeiras de poros solitários, é predominantemente paratraqueal nas espécies com múltiplos numerosos; as fibras, com pontoações tipicamente areoladas, são geralmente de comprimento médio. Traqueídeos vasicêntricos são de ocorrência comum na família, ao passo que canais intercelulares axiais, de origem traumática, são restritos a poucos gêneros. Marchiori \& Sobral (1997) comentam que o

1 Artigo recebido em 07/04/2005 e aceito para a publicação em 09/05/2005.

2 Engenheiro Florestal, Bolsista do CNPq, Doutorando do Programa de Pós-Graduação em Engenharia Florestal, Universidade Federal de Santa Maria, CEP 97105-900, Santa Maria (RS). lucianodenardi@yahoo.com.br

${ }^{3}$ Engenheiro Florestal, Dr., Professor Titular do Departamento de Ciências Florestais, Centro de Ciências Rurais, Universidade Federal de Santa Maria, CEP 97105-900, Santa Maria (RS). balduinia@mail.ufsm.br

4 Acadêmico do Curso de Graduação em Engenharia Florestal, Universidade Federal de Santa Maria, CEP 97105-900, Santa Maria (RS).markus@mail.ufsm.br 
conjunto desses caracteres sugere primitividade ao xilema das Mirtáceas. Para a maioria de suas espécies, todavia, a estrutura anatômica segue desconhecida, salientando-se, no caso do Rio Grande do Sul, os estudos sobre Feijoa sellowiana (Marchiori, 1984a), Eugenia involucrata (Marchiori, 1984b), Myrrhinium loranthoides (Marchiori, 1984c), Myrciaria tenella (Marchiori \& Muñiz, 1987a), Myrceugenia myrtoides (Marchiori \& Muñiz, 1987b), Myrceugenia glaucescens (Marchiori \& Muñiz, 1988), Calyptranthes concinna (Marchiori \& Brum, 1997), Campomanesia guazumaefolia (Marchiori, 1998) e Blepharocalyx salicifolius (Denardi, 2004).

\section{MATERIAL E MÉTODOS}

O material em estudo consiste de uma amostra de madeira e respectivo material botânico, coletados no Cerro do Loreto (São Vicente do Sul - RS) e anexados à Xiloteca e Herbário do Departamento de Ciências Florestais da Universidade Federal de Santa Maria (HDCF), sob o número 2981.

$\mathrm{Da}$ amostra de madeira, foram confeccionados três corpos-de-prova com $2 \mathrm{~cm}$ de lado, extraídos da porção mais externa do lenho e orientados para a obtenção de cortes histológicos nos planos transversal, longitudinal radial e longitudinal tangencial. Um quarto bloco foi também retirado, com vistas à maceração.

No preparo de lâminas histológicas, seguiuse a técnica padrão no Laboratório de Anatomia da Madeira da Universidade Federal do Paraná: os corpos-de-prova foram amolecidos por fervura em água e seccionados em micrótomo de deslize, regulado para a espessura nominal de $18 \mu \mathrm{m}$. Os cortes foram tingidos com acridina-vermelha, crisoidina e azul-de-astra (Dujardin, 1964), desidratados em série alcoólica, diafanizados em xilol e montados em lâminas permanentes, com "Entellan".

No preparo de lâminas de macerado, procedeu-se a dissociação do tecido lenhoso pelo método de Jeffrey (Burger \& Richter, 1991), usando-se coloração com safranina $1 \%$ e Entellan como meio de montagem.

A descrição microscópica baseou-se nas recomendações do IAWA Committee (1989) e a determinação dos diferentes tipos celulares, na metodologia proposta por Marchiori (1980). As fotomicrografias foram tomadas em aparelho Carl Zeiss, no Laboratório de Anatomia da Madeira da Universidade Federal do Paraná.

\section{DESCRIÇÃO MICROSCÓPICA}

Camadas de crescimento: distintas, marcadas por fibras radialmente estreitas no lenho tardio (Figura 1A).

Vasos: com freqüência de $54 \pm 8$ (44-61)* por $\mathrm{mm}^{2}$, medindo $41 \pm 7(30-62) \mu \mathrm{m}$ de diâmetro e em distribuição difusa; vasos geralmente solitários, em padrão diagonal ou radial, menos comumente em agrupamentos radiais de até 4 vasos (Figura 1A). Elementos vasculares de $545 \pm 83(400-760) \mu \mathrm{m}$ de comprimento, com placas de perfuração simples, oblíquas e apêndices geralmente em ambas as extremidades. Pontoações intervasculares alternas, pequenas $(5-6 \mu \mathrm{m})$ e circulares; pontoações raio-vasculares distintamente areoladas, semelhantes em tamanho e forma às intervasculares; espessamentos espiralados, tiloses e gomas, bem como traqueídeos vasicêntricos, ausentes no material em estudo.

Parênquima axial: apotraqueal difuso-emagregados (Figura 1A), disposto em séries de 4 a 8 células; eventualmente em número maior $\mathrm{e}$, por vezes, providas de cristais prismáticos em câmaras (Figura 1C).

Raios: com 1-3 células de largura e menos de $1 \mathrm{~mm}$ de altura, não estratificados (Figura 1D) e com freqüência superior a $12 / \mathrm{mm}$, compostos por células procumbentes, no centro, e 2-4 fileiras marginais de células quadradas e eretas (Figura 1B); células oleíferas, mucilaginosas e canais intercelulares, ausentes.

\footnotetext{
* $\mathrm{x} \pm \mathrm{s}$ (valor mínimo - valor máximo), onde: $\mathrm{x}=$ média; $\mathrm{s}$ $=$ desvio padrão.
} 

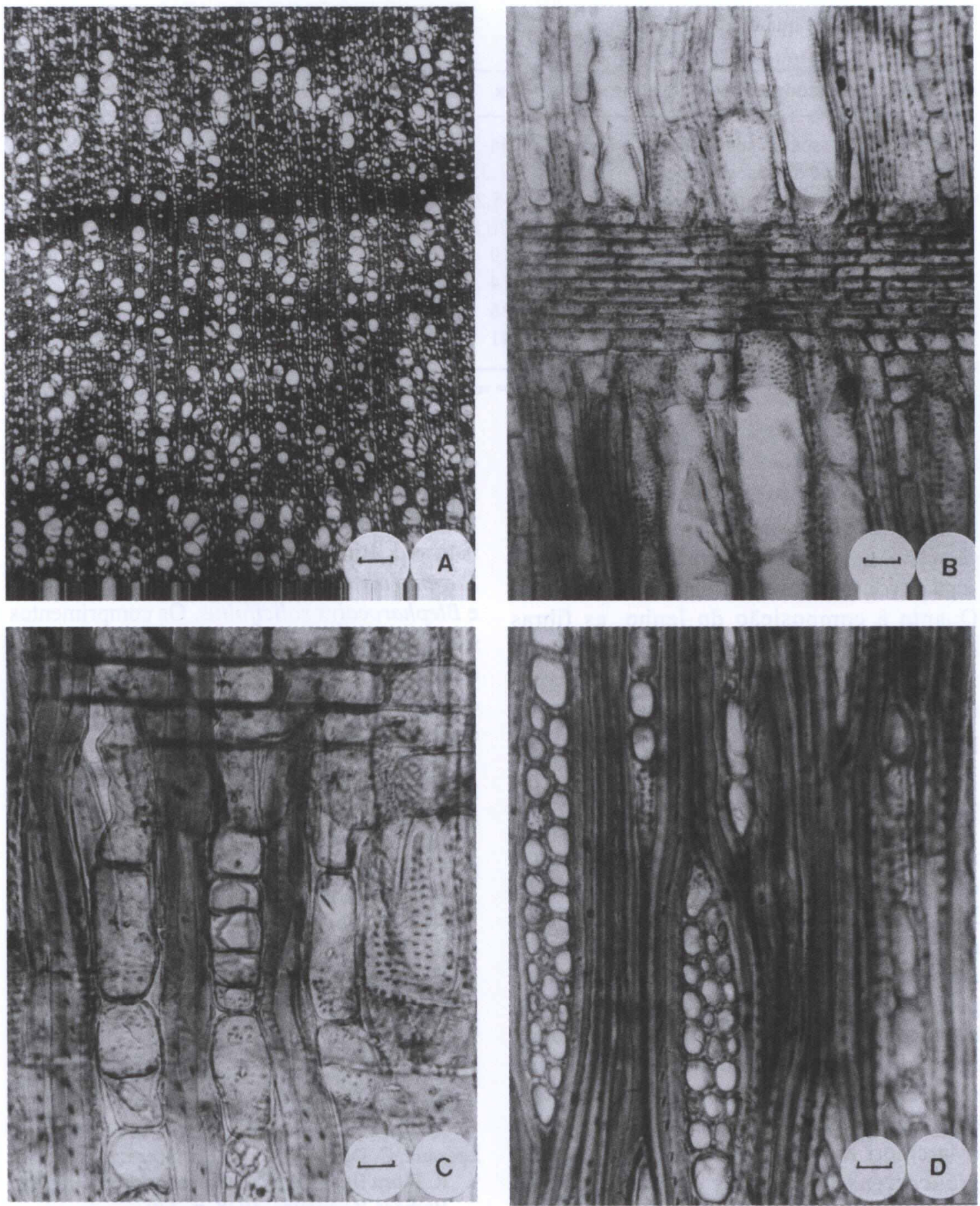

FIGURA 1 - Camadas de crescimento distintas, vasos solitários e parênquima apotraqueal difuso-emagregados, em seção transversal (A). Raios heterogêneos, com células procumbentes, quadradas e eretas, em seção longitudinal radial (B). Cristais prismáticos em células de parênquima axial e fibras com pontoações areoladas, em seção longitudinal radial (C). Raios com 1-3 células de largura e fibrotraqueídeos, em seção longitudinal tangencial (D). Escalas $=100 \mu \mathrm{m}(\mathrm{A}) ; 25 \mu \mathrm{m}(\mathrm{B}) ; 12,5 \mu \mathrm{m}(\mathrm{C}, \mathrm{D})$. 
TABELA1: Dados quantitativos da madeira.

\begin{tabular}{lccccc}
\hline Característica anatômica & $\mathrm{x}$ & $\mathrm{s}$ & $\mathrm{cv} \%$ & Mín. & Máx. \\
\hline Freqüência de vasos (vasos $\left./ \mathrm{mm}^{2}\right)$ & 54 & 7,7028 & 14,3 & 44 & 61 \\
Diâmetro do lume de vasos $(\mu \mathrm{m})$ & 41,3 & 7,0755 & 17,1 & 30 & 62,5 \\
Comprimento de elementos de vaso $(\mu \mathrm{m})$ & 545,2 & 83,1224 & 15,2 & 400 & 760 \\
Comprimento de fibras $(\mu \mathrm{m})$ & 1170,8 & 260,0408 & 22,2 & 750 & 1750 \\
Fração de vasos (\%) & 19 & 2,3664 & 12,4 & 16 & 22 \\
Fração de parênquima axial (\%) & 14 & 6,1128 & 43,7 & 8 & 23 \\
Fração de raios (\%) & 26 & 5,8195 & 22,4 & 17 & 33 \\
Fração de fibras (\%) & 41 & 2,3166 & 5,6 & 38 & 45 \\
\hline
\end{tabular}

$\mathrm{x}=$ média; $\mathrm{s}=$ desvio padrão; $\mathrm{cv}$ = coeficiente de variação; Mín. = valor mínimo; Máx. = valor máximo; $\mu \mathrm{m}=$ micrômetros;

Fibras: de $1170 \pm 260(750-1750) \mu \mathrm{m}$ de comprimento e paredes muito espessas, com pontoações distintamente areoladas nos dois planos longitudinais (Figura 1C,D); fibras septadas e espessamentos espiralados, ausentes. Quanto à composição do lenho, as fibras correspondem a $41 \%$ do total, seguida pelos raios $(26 \%)$, vasos $(19 \%)$ e parênquima axial (14\%); máculas medulares, eventualmente presentes.

\section{ANÁLISE DA ESTRUTURA ANATÔMICA}

A estrutura anatômica da madeira de Plinic rivularis concorda, em linhas gerais, com o descrito por Metcalfe \& Chalk (1972) para as Mirtáceas. A presença de poros solitários e em distribuição difusa, de placas de perfuração simples, de fibras com pontoações areoladas, de parênquima apotraqueal e de raios heterogêneos, tidos como predominantes na família, foram. também observacios em Feijoa sellowiana (Marchiori, 1984a), Myrrhinium loranthoides (Marchiori, 1984c), Myrceugenia myrtoides (Marchiori \& Muñiz, 1987b), Myrceugenia glaucescens (Marchiori \& Muñiz, 1988), Calyptranthes concinna (Marchiori \& Brum, 1997), Campomanesia guazumaefolia (Marchiori, 1998) e Blepharocalyx salicifolius (Denardi, 2004). Em plano transversal, os poros dão a falsa impressão de serem exclusivamente solitários; em exame detalhado, todavia, cerca de $20 \%$ dos mesmos ocorrem em pequenos múltiplos. Com relação aos cristais, eles foram também encontrados em outras Mirtoídeas nativas do Rio Grande do Sul: Feijoa sellowiana, Eugenia involucrata, Myrrhinium loranthoides e Blepharocalyx salicifolius. Os comprimentos médios de fibras e elementos de vaso, bem como a freqüência de vasos, situam-se, no material em estudo, dentro da amplitude verificada para o conjunto de espécies anteriormente considerado.

\section{BIBLIOGRAFIA}

Burger, L. M., Richter, H. G. Anatomia da Madeira. São Paulo: Ed. Nobel, 1991. 154 p.

Denardi, L. Estudo anatômico do lenho e morfologia foliar de Blepharocalyx salicifolius (H.B.K.) Berg, em duas regiões do Rio Grande do Sul. Santa Maria: UFSM, 2004. 94f. Dissertação (Mestrado em Engenharia Florestal) - Universidade Federal de Santa Maria.

Lujardin, E. P. Eine neue Holz-zelltlosenfaerbung. Mikrokosmos, n. 53, p. 94, 1964.

IAWA Committee. IAWA list of microscopic features for hardwood identification. IAWA Bull., v. 10, n. 3, p. 218-359, 1989.

Legrand, C. D., Klein, R. M. Mirtáceas. In: Reitz, P. R. Flora Ilustrada Catarinense. Itajaí: Herbário Barbosa Rodrigues, 1978. p. 770.

Marchiori, J. N. C. Estudo anatômico do xilema secundário de algumas espécies dos gêneros Acacia e Mimosa, nativas no Estado do Rio Grande do Sul. Curitiba: UFPR, 1980. 186f. Dissertação (Mestrado em Engenharia Florestal) - Universidade Federal do Paraná. 
Marchiori, J. N. C. Anatomia descritiva do lenho de Feijoa sellowiana Berg. Ciência \& Natura, Santa Maria, v. 6, p. 117-125, 1984a.

Marchiori, J. N. C. Anatomia da madeira de Eugenia involucrata DC. (Myrtaceae). Ciência \& Natura, Santa Maria, v. 6, p. 127-136, 1984b.

Marchiori, J. N. C. Anatomia descritiva da madeira de murtilho, Myrrhinium loranthoides (Hook. et Arn.) Burret, Myrtaceae. Rev. Centro de Ciências Rurais, Santa Maria, v. 14, p. 43-50, $1984 c$.

Marchiori, J. N. C. Estudo microscópico da madeira de sete-capotes, Campomanesia guazumaefolia (Camb.) Berg, Myrtaceae. Ciência Rural, Santa Maria, v. 28, n. 1, p. 47-51, 1998.

Marchiori, J. N. C., Muñiz, G. I. B. Estudo anatômico da madeira de Myrciaria tenella (DC.) Berg. Ciência \& Natura, Santa Maria, v. 9, p. 97-103, 1987a.

Marchiori, J. N. C., Muñiz, G. I. B. Anatomia descritiva da madeira de Myrceugenia myrtoides
Berg. Ciência \& Natura, Santa Maria, v. 9, p. 113-120, $1987 \mathrm{~b}$.

Marchiori, J. N. C., Muñiz, G. I. B. Estudo anatômico da madeira de Myrceugenia glaucescens (Camb.) Legrand et Kausel. Ciência \& Natura, Santa Maria, v. 10, p. 105-113, 1988.

Marchiori, J. N. C., Brum, E. T. Anatomia da madeira do guamirim-facho, Calyptranthes concinna DC. Ciência Rural, Santa Maria, v. 27, n. 2, p. 217 222, 1997.

Marchiori, J. N. C., Sobral, M. Dendrologia das angiospermas: Myrtales. Santa Maria: Ed. da UFSM, 1997. 304p.

Metcalfe, C. R., Chalk, L. Anatomy of the Dicotyledons. Oxford: Clarendon Press, 1972. v. 2 , p. 621 .

Rotman, A. D. Los géneros Calycorectes, Hexachlamys, Myrciaria, Paramyrciaria, Plinia y Siphoneugena en la flora argentina. Darwiniana, San Isidro, v. 24, n. 1-4, p. $157-$ 185,1982 . 